MAhiQues Climent, Joan: Els morts agraïts. Manacor: Món de Llibres, 20i6, i96 p.

\title{
Els morts agraïts
}

Rafael BELTRAN LLAVADOR

Universitat de València

Qualsevol aproximació monogràfica a motius, temes o arguments (tipus) folklòrics és i serà sempre complexa. El llibre de Mahiques Climent, guanyador del Premi Ciutat de Manacor d'Assaig Antoni M. Alcover, 20I6, des del seu títol ben suggeridor, Els morts agraïts, significa una arriscada aposta per aplicar una certa lògica del relat a un tema força desconegut, aposta engrescada i aplicada sense les restriccions formals que, a vegades, tenallen els treballs primerencs dins el camp de la rondallística. L'autor té experiència sobrada en l'estudi de les literatures clàssiques hispàniques, i, en concret, dins l'àmbit que ens afecta, ha treballat anteriorment amb rigor en relats i històries de difunts tractats per les cròniques, les llegendes i les ficcions. I aquí ens planteja un ambiciós recorregut per la rondallística catalana i europea, al voltant d'una frondosa espècie arbòria amb tantes ramificacions que resulta difícil tractar amb arguments expositius directes o diàfans. El tema de la mort dibuixa una línia bisectriu que travessa el cor d'un gran nombre de rondalles, atès que forma part essencial del pensament racional i simbòlic, i de molts relats que formen la mitologia de tots els pobles del món. I el tema del mort agraït seria una secció petita — gens menyspreable — al mig d'aquesta línia central o bisectriu. Una línia que, forçosament, s'esmuny i s'escola per diferents roquissars o estrets viaranys que condueixen a infinites branques. Dispersió positiva, perquè ens fa visitar passatges desconeguts. Tractant-se de morts, com és el cas, il-luminarà la tenebra dels àmbits descoberts, descrits i analitzats.

L'autor es proposa l'estudi d'un cicle de rondalles que empara com a eix central el motiu del mort agraït, classificat entre el núms. 505 i 508 per Aarne i Thompson, ${ }^{\mathrm{I}}$ classificació revisada per Uther. ${ }^{2}$ El denominador comú d'aquests tipus o famílies de relats expressa, d'una banda, l'acte caritatiu d'un jove envers un difunt (el soterrament o el pagament d'un sepeli), i, d'altra, el casament de l'heroi amb una jove, després de superar tot un seguit d'obstacles i gràcies a l'ajut del difunt que havia auxiliat, és a dir, gràcies al mort que es mostra just i agraït. S'hi examinen una majoria de testimonis en català (unes quaranta «rondalles funeràries»), tot i que l'assaig situa aquesta rondallística i aquest llegendari dins la tradició folklòrica i la literària universal, des de l'època medieval fins avui. La relació dels arguments estudiats amb creences religioses, ritus funeraris i cultes de les ànimes permet ampliar l'abast de l'estudi a interpretacions històriques, antropològiques o socials. La reversibilitat de favors entre vius i morts és pròpia de totes les cultures teocèntriques (és a dir, de quasi totes les cultures) no només de les cristianes; de manera que la idea cristiana al voltant que el fidels hem de contribuir al descans o al ràpid passatge dels patiments dels difunts al llarg del seu trànsit cap al cel per

I AARne, Anti; Stith ThOMPson ([1928] 1973): The Types of the Folktale. A classification and Bibliography. Folklore Fellows' Communications I84. Hèlsinki: Suomalainen Tiedeakatemia.

2 UTHER, Hans-Jörg (2004): The Types of International Folktales. A classification and Bibliography. Based on the System of Antti Aarne and Stith Thompson. 3 vols. Folklore Fellows' Communications 284-285-286. Hèlsinki: Suomalainen Tiedeakatemia. 
mitjà d'oracions, però també de bones accions, es confirma com una idea universal, des del món pagà, com també ho seria la creença que els difunts intercedeixen i vetllen per nosaltres, i ens preserven dels mals.

Mahiques sembla cercar l'aproximació al tema dels morts agraïts amb la geometria latent d'un dibuix de cercles (capítols) que haurien d'anar concèntrics, de l'exterior a l'interior, dirigits cap a l'os o cor del tema, cap als arguments principals en la diana central. Tanmateix, tractant-se de temes folklòrics, aquest apropament ha ser per necessitat amb cercles exteriors, secants o tangents, però no - per impossibilitat- concèntrics o simètrics. El primer, més ample i exterior d'aquests cercles afectaria la relació del protagonista de les rondalles funeràries, és a dir, el jove heroi caritatiu, amb els seus benefactors (capítol II: «No només els difunts són agraïts»). El donador, ésser itinerant, a la recerca d'allò que li manca (amor, fortuna) ajudarà, en l'itinerari del seu viatge iniciàtic, el vellet o la velleta, o el desconegut, home o bèstia (a vegades un àngel, sovint un cavall), benefactors antropomòrfics o animals. El desconegut agraït podrà ser, doncs, un difunt, però també un sant, o la Verge, o el seu Fill, o una fada. Allò cert, en tot cas, és que el repàs d'algunes d'aquestes narracions, que Mahiques selecciona i comenta amb fluïdesa, ofereix un observatori distanciat per resseguir i comprovar com els arguments perpetuen una cadena de favors mutus, segons la qual el jove generós ajuda el difunt (o altre ésser viu) a fer el seu darrer viatge, mentre que, en paral·lel, ell emprèn un altre viatge, en el seu cas vital, iniciàtic, perillós i extraordinari, més enllà de la quotidianitat, per la qual cosa demanarà l'ajut sobrenatural de l'altre «viatger».

El cicle del mort agraït (capítol III), estudiat des de Gerould ${ }^{3}$ fins a Belmont, ${ }^{4}$ conté, en la més moderna classificació d'Uther, tres tipus bàsics: The Grateful Dead (ATU 505), Prophecy Escaped (ATU 506) i Monster's Bride (ATU507). En comú a tots tres, el viu costeja o fa possible la sepultura del difunt, que li havia estat negada per pobresa o deutes. Agraït, però amagat darrere l'anonimat, el difunt salva la vida del benefactor i li atorga mitjans per poder arribar a un estatus elevat (casar-se amb una princesa, etc.). La presentació i l'anàlisi del relat primigeni del Llibre dels fets de Tobit és essencial. El ritual de Tobies, qui pren cura del seu pare, Tobit, gràcies a la cremació del cor i el fetge d'un peix molt gros, amb un fum que fa fugir el dimoni, i li cura la vista amb la fel del mateix peix, es repetirà en diverses rondalles del cicle d'ATU 507, on l'esposa és posseïda per un ésser maligne i l'heroi la purifica, o bé seccionant-la a trossos, o bé cremant-la. L'exemple d' «Es cavallet de set colors» d'Alcover resulta del tot pertinent, si bé entrem, amb aquesta rondalla —em permet suggerir_-, en relacions amb una altra sèrie de rondalles que es poden classificar com a 5O7, però també amb el tipus d'ATU 3I4 (Goldener) i que afectarien d'altres recollides pel mateix Alcover, com ara «En Mercè-Mercè» [I896], difícils de classificar (com reconeixen Grimalt i Guiscafrè, els seus editors), o castellanes, amb el mateix argument, com ara «El caballo de siete colores» de Juan de Ariza (I848). Rondalles que tenen precedents en les Mil i una nits (en la versió de Mardrus, de I889) i testimonis de variants amb molta influència, com

3 Gerould, Gordon Hall (I908): The Grateful Dead. The History of a Folk Story. Londres: David Nutt for the Folk-LoreSociety.

4 Belmont, Nicole (I999): «La dette et le contrat. Jean de Calais: les versions du 'Mort reconnaissant' dans la tradition française». Cahiers de Litttérature Orale, núm. 46: I27-I47. 
ara «El gnom»o «L'aigua de la vida», dels germans Grimm, o en l'àrea del català, «Les tres princeses encantades», de Serra i Boldú, o «Esclafamuntanyes», d'Enric Valor. La mateixa manca de definició argumental clara amb el grup estudiat (Uther en planteja els entrecreuaments, dels dos tipus) crec que tindrien les històries relacionades amb la princesa deslliurada per l'esclavitud, que encapçala, en l'estudi de Mahiques, L'histoire de Jean de Calais (I723), de Madeleine-Angelique de Gomez. Indubtablement, hi és el motiu del mort agraït, però dins un relat que gira més aviat al voltant del tema de Constance o la donzella perseguida. És en aquest capítol on trobe una possible indefinició entre motius folklòrics i tipus (arguments) que hi hagués resultat molt útil (no entenc referència bibliogràfica que atribueix el Motif-Index de motius a Aarne i Thompson, quan és obra exclusiva del segon).

Al capítol IV («El mercader, el difunt i l'esclava») s'estudien vuit rondalles catalanes, l'argument de les quals pertany al tipus ATU 505, amb jove que despèn els diners per comprar la sepultura d'un home; després el jove, tirat de sa casa pels pares, lliurarà de l'esclavatge una noia, gràcies a l'ajuda del mort agraït. Especialment interessant (tot i que semble digressiu respecte al tema central del llibre) és el capítol sobre el reconeixement dels familiars a partir de la música, on porten a col-lació capítols extraordinaris d'obres medievals, com ara la versió castellana d'El libro de Apolonio, i tipus complementaris, com els de La flor del panical.

El capítol v, «Ritus i relíquies de difunts» dibuixa un altre cercle tangent que s'apropa al tema del cicle estudiat, fregant-lo encara de gaidó. El tema de l'enterrament és repassat, des del mite clàssic d'Antígona fins a les llegendes hagiogràfiques medievals i el Recull d'exemples d'Arnau de Lieja. Aquest darrer forneix, efectivament, un material inesgotable d'històries sobre difunts, enterraments, dimonis, venjances, etc. que l'autor coneix bé. El problema és que el tema del viatge dels difunts té tantes implicacions narratives i antropològiques que no es poden ni tan sols resumir en un capítol. Així, els comentaris de les versions de «Sa llàmpria meravellosa», d'Alcover, o «El ferrer de Bèlgida», de Valor, tot i que exposen el motiu del viàtic, resten insuficients i el lector es pot preguntar fins a quin punt en són representatives, entre desenes d'altres.

El capítol VI, «La profecia eludida» és el primer apartat que comenta el segon dels tipus estudiats (ATU 506: Prophecy Escaped), on, molt resumidament, el noi naix maleït per la profecia que diu que morirà penjat de jove; però ajudarà un desconegut o company (difunt o sant) que li tornarà el favor, salvant-li la vida i fent-li guanyar una princesa, amb la condició que aquesta siga seccionada (mig tallada). Mahiques estudia en aquest cas quatre rondalles en català, cinc en castellà i una de portuguesa. I examina la prova de l'amistat, amb especial atenció a algunes versions atípiques. El mateix tema i tipus segueix en el capítol viI («El penjat despenjat»). Com es reconeix, en els exemples estudiats «no hi ha cap mort agraït» (p. II2). L'estructura argumental, tanmateix, es manté. Les versions presentades, tant les dues versions còmiques d'Alcover com les presències plurals del motiu en el Codex Calixtinu, en l'Espill de Jaume Roig, o dins algunes llegendes urbanes, donen testimoni que es tracta d'una amplificació novament externa o tangencial al tema del mort agraït, que mereixeria un tractament específic, potser amb aportacions complementàries - per què no? - de la rica iconografia sobre penjats des de l'edat mitjana. 
El capítol VIII, «Destí versus providència», continua desenvolupant els motius del tipus 506 Prophecy Escaped, ara amb tractament del tema del designi diví. L'autor ens prevé davant la temptació d'interpretar-lo des d'un punt de vista actual, de lluita entre la llibertat individual i el fatum. «La providència divina no erra mai i pot canviar el destí de les persones si és per un bé major» (p. I35). Les afirmacions de Mahiques, al voltant del fet que «en la literatura folklòrica són més importants l'heroi, la trama argumental i el desenvolupament de l'acció» que no les disquisicions morals (cita Voltaire), i que «els personatges que protagonitzen les versions del cicle del mort agraït tenen un cor bondadós, i precisament per això no es veuen desemparats i superats per un destí tràgic, atroç i inexorable» (p. I37), podrien ser matisades — també aprofundides — amb les aportacions d'altres, estudis sobre la rondalla catalana, i en especial amb el recent de Josep Temporal, que guanyà el mateix Premi de Manacor, el 20I3, i que va publicar la mateixa editorial que publica el llibre de Mahiques. ${ }^{5}$ La tesi de Temporal manifesta que la presència de la virtut en els personatges de les rondalles és més espontània que premeditada, perquè és una virtut natural. L'acció de les rondalles meravelloses s'hi concep com el resultat de la virtut i l'acompliment de la tasca pròpia de cada personatge, i les rondalles meravelloses palesen un reflex dels objectius de les accions amb sentit i del fi últim (teleològic), constitutius de la realitat humana. ${ }^{6}$ Aquesta orientació teleològica, com la defineix Temporal, donaria raó i fonamentació antropològica i ètica precisament al tema important que planteja Mahiques: els personatges de les rondalles no poden ser tràgics, d'igual manera que tampoc es poden comparar els seus processos d'actuació amb les evolucions psicològiques dels personatges de novel-la o conte escrit.

El capítol IX tracta el tema de les filadores (ATU 50I, Three Old Spinning Women), ben estudiat per José Manuel Pedrosa (es remet al seu treball) des del punt de vista antropològic. Tres versions catalanes importants (d'Alcover, Amades i Valor) són analitzades en col·lació amb deu d'hispàniques, moltes influïdes per la potent versió dels germans Grimm (la mateixa versió que s'inclou de Cecilia Böhl de Faber). Jaume Albero és el crític que ha analitzat més a fons, amb rigor i en la línia de Mahiques - pense- les rondalles de Valor. ${ }^{7}$ Les conclusions tanquen el cercle més estret de l'assaig de Mahiques: «la devoció a les ànimes del Purgatori garanteix l'èxit de la felicitat de la protagonista [...]. Els vius ajuden els difunts amb els sufragis - misses, almoines, oracions, etc. - i els difunts també responen sol-lícitament, perquè els morts mai no deixen de ser agraïts» (p. I57).

Finalment, el capítol x («El favor i la promesa, a manera d'epíleg») examina - de manera potser una mica accelerada per arribar a articular unes bones conclusions - un altre grup de nou rondalles (set catalanes), on l'heroi promet al benefactor d'ultratomba que li donarà la meitat dels béns que ha de guanyar; en molts casos, el compliment de la promesa significa partir per la meitat l'esposa o el fill o els fills. En totes les versions la mà de l'executor és aturada abans de l'acte fatal. Però, efectivament, a diferència del relat de sacrifici bíblic —Abraham i Isaac-,

5 TEMPORAL, Josep (2OI4): Rondalla meravellosa i filosofia. Una fonamentació antropologicoètica. Manacor: Món de Llibres.

6 Vegeu la ressenya de Gemma Lluch, dins Estudis de Literatura Oral Popular, núm. 4 (20I5: I86-I88).

7 Estudia «Les animetes», en La memòria reinventada: l'univers rondallístic d'Enric Valor. València: Alfons el Magnànim, 20I2, p. I97-208. 
Reviews

desapareix el sentit dramàtic religiós, o la pietat de la llegenda o exemplum medieval, i tot passa dins el camp de la meravella. Per això l'ajudant ja no és un àngel del Senyor, sinó un mort agraït.

El llibre de Mahiques sobre els morts agraïts de les rondalles catalanes és alhora rigorós i clàssic, innovador i engrescador. És tot un repte l'aplicació d'una metodologia crítica no estrictament formalista en l'estudi d'un tema molt suggeridor i complex dins la rondalla meravellosa. I es fa des del coneixement i el respecte de tota la tradició d'estudis folklòrics, amb postulats amples i ambiciosos, que permeten l'avaluació i la contextualització històrica, l'aportació i el diàleg amb altres obres europees medievals i modernes, i que obrin la porta per a posteriors treballs de caire literari i antropològic. 